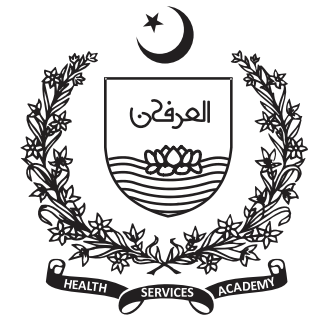

${ }^{1}$ Associate Professor, Department of Community Medicine, HITEC-IMS, Taxila

${ }^{2}$ Lecturer, Department of Community Medicine, HITECIMS, Taxila

3 Senior Lecturer, Community Medicine, Rawalpindi Medical University

${ }^{4}$ Final Year MBBS, Rawalpindi Medical University,

Rawalpindi

${ }^{5}$ Assistant Professor, Department of Community Medicine, HITEC-IMS, Taxila

Corresponding author

Bushra Anwar

Email: bushra.anwar@live.com

\section{Assessment of Health literacy and its determinants in patients visiting tertiary care hospital, Rawalpindi, Pakistan}

\author{
Aashi Ahmed ${ }^{1}$, Bushra Anwar², Mehjabeen Qureshi ${ }^{3}$, Maliha Asim4, Nadia \\ Nisar $^{5}$
}

\begin{abstract}
Background: Health literacy refers to the ability to access, understand and use health related information to promote good health. It is required to achieve good health of an individual. Good health literacy has been shown to improve health outcomes of a person and is now the focus of many researches internationally. The objective of the study was to assess health literacy levels and its determinants in patients visiting tertiary care hospital in Rawalpindi
\end{abstract}

Methods: This cross-sectional survey was conducted in three public sector tertiary care hospitals in duration of four months. 450 adults of either gender with age > 18 years capable of providing informed consent and able to communicate in any of the local languages were selected from outpatient and emergency departments. The data entry and statistical analysis were done using SPSS version 23.

Results: $26.2 \%$ of people had poor health literacy, $56.4 \%$ had satisfactory health literacy whereas only $17.3 \%$ had good health literacy. Health literacy was poorest in domain of disease prevention (lowest mean score of 2.3+.86). Mean health literacy was significantly positively associated with higher income, and higher frequency of watching health-related television programs.

Conclusion: Health literacy levels were found to be low in our study population. Gaps in health literacy should be addressed by more research and interventions. The health educators (health care professionals) can play a major role in helping to enhance the health literacy and act as an advocate for health education.

Key words: Health literacy; health promotion; delivery of health care; prevention and control

\section{Introduction}

$\mathrm{H}$ literacy' refers to the cognitive and social skills which motivate and enable individuals to access, understand and use health related information to promote good health. It is determined by the personal skills to read the system as well as the complexity or readability of the system (1). Health literacy is a newer and evolving concept in health promotion (2). It empowers individuals to adopt healthy lifestyles and make sound decisions regarding healthcare, gaining control over their health (3). It has been suggested that inadequate health literacy can lead to poor health outcomes including anxiety, dissatisfaction with healthcare and increased risk of hospitalization (3). Its linking pathway with poor health can be via unhealthy behaviors resulting from poor health literacy, or it can be via social factors like feelings of 
shame, loneliness and lack of social support linked with poor health literacy (4).

Research on health literacy has increased internationally in the last decade. Highest contribution has been seen in Switzerland, Netherlands, UK, Japan, Korea and Australia. It is explicitly mentioned as an area of priority action in the European Commission's Health Strategy. The American Medical Association also recommends conducting more research on poor health literacy, with a focus on its different aspects; screening and interventions for low-literacy patients, its costs and outcomes, and causal pathways of poor health outcomes (1).

As much as the science of screening poor literacy is developing, (2) It is being perceived as a challenge to measure health literacy because of the subjective components of knowledge and motivation involved (5). However, the European consortium has been successful in designing a tool with help of international health literacy experts. Their tool named as the European Health Literacy Assessment tool has been validated in Europe, Japan, and Taiwan. Several short-forms of this questionnaire have also been developed to provide easy assessment of health literacy in the individuals $(6,7)$. The tools measured four main functions of health literacy (access, understand, process and apply information) relevant to three main aspects of health (health promotion, disease prevention and health care) (8).

Health literacy is more critical for developing countries, where a heavy burden of diseases is catered by a poor healthcare infrastructure, and good health literacy could have saved people from getting unsafe care and enabled their self-care. Pakistan also faces a bogged down health system due to multiple issues. Many health providers still function in traditional allknowing roles, many a times making uninformed decisions for their patients. Low health literacy further complicates the situation by late presentation of fatal illnesses (9). A Pakistani study reported that half of the patients studied didn't fully understand physician instructions and medication use. This low literacy combined with linguistic barriers makes them vulnerable to disadvantages of poor healthcare system (10). Few other researches regarding health literacy have been done in Lahore and some other cities of Punjab $(11,12)$.

We could not find any research published on health literacy of population in Rawalpindi, Islamabad. In this study, we aimed to find facts about health literacy in our local people. This study will not only help in assessing the health literacy level of our people but also sensitize public health authorities about this issue which is being considered a neglected topic for research in our country. Data from this study will reinforce the importance of health literacy in adequate patient compliance and self-care.

\section{Methodology}

Study design and sampling methodology:

This study was designed as a cross sectional descriptive survey and conducted in a duration of four months from March to June, 2018. Patients visiting Outdoor Patients Department (OPD) of a tertiary care institute in the city of Rawalpindi, Pakistan were included in the study.

Inclusion criteria:

450 adult clinically stable patients of either gender capable of providing informed consent and able to communicate in any of the local languages were randomly selected from outpatient and emergency departments. Informed consent was taken from the patients before their interview. Confidentiality of their data was ensured.

Study instrument:

Data was collected by using a pre-validated questionnaire. The questionnaire included questions from a short form health literacy questionnaire designed by European Consortium (13). This questionnaire was translated into Urdu and was pilot tested among 50 patients for reliability. The reliability of the translated tool was determined by calculating Cronbach's Alpha that proved it to be highly reliable with Cronbach's Alpha value .806 as a whole. So this questionnaire was approved for final study. To assess health literacy levels, there were a total of 12 questions regarding patient's ability to access, understand and use health related information in three domains of health i.e. health promotion, disease prevention and health care. Questions were asked from the patients by our data collectors and answers were recorded on a scale from very easy to very difficult.

Data analysis:

The data was analyzed using the SPSS $\mathrm{v}$ 21.0. The individual parameters were assessed for their percentage contribution in determining health literacy and the prevalence of each parameter among the samples under study. Data from pilot study was not included in the final analysis. 


\section{Results}

The mean age of 450 respondents was 37.6 years $(\mathrm{SD} \pm$ 13.1Years). Out of total 450 respondents, 195 (43.3\%) were male and $255(56.7 \%)$ were females. Regarding working status of respondents, $202(44.9 \%)$ were working, 243 (54\%) were not working and $5(1.1 \%)$ were students. Out of working people, majority 77 $(38.1 \%)$ were having private jobs, $38(18.8 \%)$ had their own business, 19 (9.4\%) had government job. 31 $(15.3 \%)$ had jobs related to education, $15(7.4 \%)$ had commerce related jobs and $22(10.8 \%)$ had other jobs. Majority 191 (42.4\%) respondents had 1-10 years of education, $14(3.1 \%)$ had more than 16 years of education and only 17 (3.8\%) were illiterate.

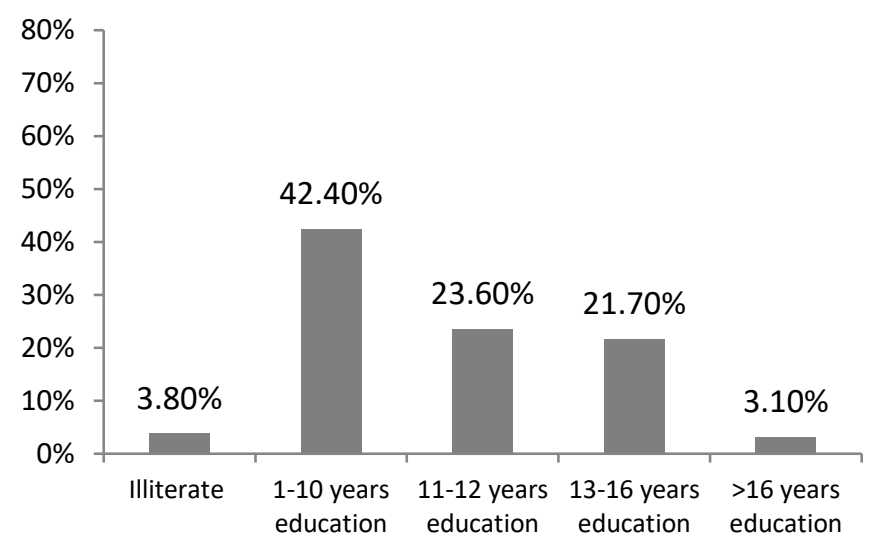

Figure.1. Educational status of respondents $(n=450)$

Majority of the participants were from lower income group. $136(30.2 \%)$ respondents had monthly income less than 10,000 Rs. 155 (34.4\%) had 10,000- 20,000 Rs. monthly income, 98 (21.8\%) between 20,000-30,000 Rs., $37(8.2 \%)$ between 30,000 to 40,000 Rs. and 24 (5.3\%) had monthly income above 40,000 Rs.

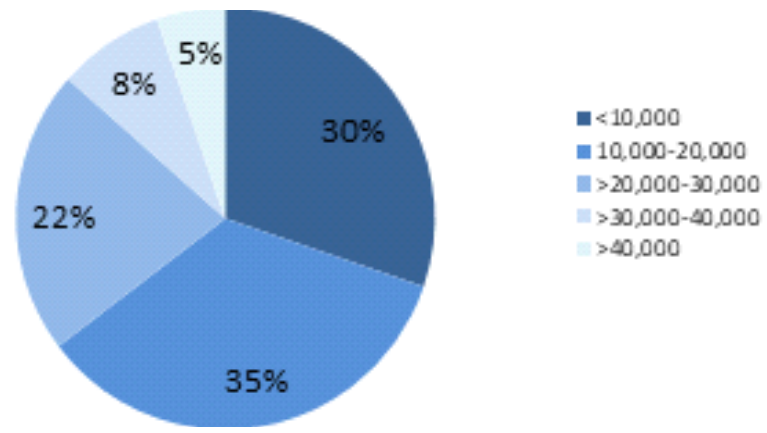

Figure 2. Monthly income of participants $(n=450)$

Self-reported socioeconomic status of participants showed that majority $(54.2 \%)$ belonged to middle class while only $3(0.7 \%)$ belonged to upper class as shown in figure 3.

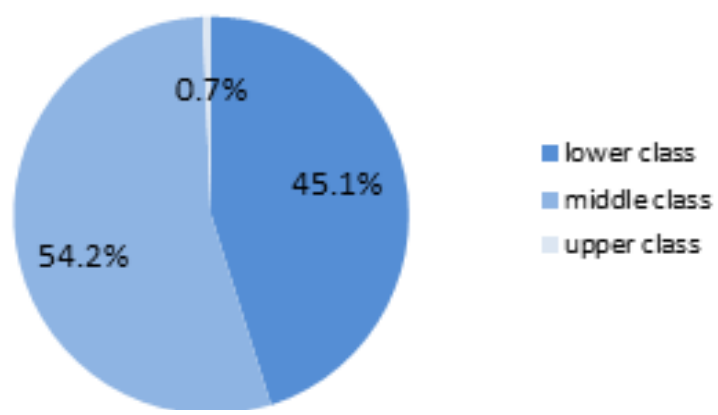

Figure 3. Socioeconomic status of respondents $(n=450)$

More than half of the participants often watch health related programs on television i.e. 240 (53.3\%). 41 $(9.1 \%)$ responded to mostly watch health related programs, whereas 169 (37.6\%) had never seen health related programs on Television. Responses to health literacy questions in different domains of health showed that health literacy was poorest in domain of disease prevention (lowest mean score of 2.3+.86); refer to table 1 for other questions. 
Table 1. Frequency of responses to study variables $(n=450)$

\begin{tabular}{|c|c|c|c|c|c|c|}
\hline \multirow[t]{2}{*}{ Domain } & \multirow[t]{2}{*}{ Variable } & \multicolumn{4}{|l|}{ Response } & \multirow{2}{*}{$\begin{array}{l}\text { Mean Score } \pm \\
\text { SD }\end{array}$} \\
\hline & & $\begin{array}{l}\text { Very } \\
\text { difficult }\end{array}$ & Difficult & Easy & Very easy & \\
\hline \multirow[t]{4}{*}{ Health Care } & $\begin{array}{l}\text { To find information on treatments of } \\
\text { illnesses that concerns you? }\end{array}$ & $\begin{array}{l}112 \\
(24.9 \%)\end{array}$ & $\begin{array}{l}133 \\
(29.6 \%)\end{array}$ & $\begin{array}{c}113 \\
(25.1 \%)\end{array}$ & $\begin{array}{l}92 \\
(20.4 \%) \\
\end{array}$ & \multirow{4}{*}{$2.4+.88$} \\
\hline & $\begin{array}{l}\text { To understand the leaflet that comes with } \\
\text { your medicine? }\end{array}$ & $\begin{array}{l}136 \\
(30.2 \%)\end{array}$ & $\begin{array}{l}113 \\
(25.1 \%)\end{array}$ & $\begin{array}{l}99 \\
(22 \%)\end{array}$ & $\begin{array}{l}102 \\
(22.7 \%)\end{array}$ & \\
\hline & $\begin{array}{l}\text { To judge the advantages and disadvantages } \\
\text { of different treatment options? }\end{array}$ & $\begin{array}{l}116 \\
(25.8 \%)\end{array}$ & $\begin{array}{l}121 \\
(26.9 \%)\end{array}$ & $\begin{array}{l}122 \\
(27.1 \%)\end{array}$ & $\begin{array}{l}91 \\
(20.2 \%)\end{array}$ & \\
\hline & To call an ambulance in an emergency? & $\begin{array}{l}120 \\
(26.7 \%)\end{array}$ & $\begin{array}{l}105 \\
(23.3 \%)\end{array}$ & $\begin{array}{l}90 \\
(20 \%)\end{array}$ & $\begin{array}{l}135 \\
(30 \%)\end{array}$ & \\
\hline \multirow[t]{4}{*}{$\begin{array}{l}\text { Disease } \\
\text { Prevention }\end{array}$} & $\begin{array}{l}\text { To find information on how to manage } \\
\text { mental health problems like stress or } \\
\text { depression? }\end{array}$ & $\begin{array}{l}130 \\
(28.9 \%)\end{array}$ & $\begin{array}{l}120 \\
(26.7 \%)\end{array}$ & $\begin{array}{l}119 \\
(26.4 \%)\end{array}$ & $\begin{array}{l}81 \\
(18.0 \%)\end{array}$ & \multirow[t]{4}{*}{$2.3 \pm .86$} \\
\hline & $\begin{array}{l}\text { To understand why you need health } \\
\text { screenings (such as breast exam, blood sugar } \\
\text { test, blood pressure)? }\end{array}$ & $\begin{array}{l}143 \\
(31.8 \%)\end{array}$ & $\begin{array}{l}119 \\
(26.4 \%)\end{array}$ & $\begin{array}{l}91 \\
(20.2 \%)\end{array}$ & $\begin{array}{l}97 \\
(21.6 \%)\end{array}$ & \\
\hline & To judge which vaccinations you may need? & $\begin{array}{l}141 \\
(31.3 \%) \\
\end{array}$ & $\begin{array}{l}119 \\
(26.4 \%)\end{array}$ & $\begin{array}{l}93 \\
(20.7 \%)\end{array}$ & $\begin{array}{l}97 \\
(21.6 \%)\end{array}$ & \\
\hline & $\begin{array}{l}\text { To decide how you can protect yourself from } \\
\text { illness based on advice from family and } \\
\text { friends? }\end{array}$ & $\begin{array}{l}100 \\
(22.2 \%)\end{array}$ & $\begin{array}{l}119 \\
(26.4 \%)\end{array}$ & $\begin{array}{l}103 \\
(22.9 \%)\end{array}$ & $\begin{array}{l}128 \\
(28.4 \%)\end{array}$ & \\
\hline \multirow[t]{4}{*}{$\begin{array}{l}\text { Health } \\
\text { promotion }\end{array}$} & $\begin{array}{l}\text { To find out about activities (such as } \\
\text { meditation, exercise, walking, Pilates etc.) } \\
\text { that are good for your mental well-being? }\end{array}$ & $\begin{array}{l}89 \\
(19.8 \%)\end{array}$ & $\begin{array}{l}70 \\
(15.6 \%)\end{array}$ & $\begin{array}{l}126 \\
(28 \%)\end{array}$ & $\begin{array}{l}165 \\
(36.7 \%)\end{array}$ & \multirow[t]{4}{*}{$2.5 \pm .86$} \\
\hline & $\begin{array}{l}\text { To understand information in the media } \\
\text { (such as Internet, newspaper, magazines) on } \\
\text { how to get healthier? }\end{array}$ & $\begin{array}{l}105 \\
(23.3 \%)\end{array}$ & $\begin{array}{l}47 \\
(10.4 \%)\end{array}$ & $\begin{array}{l}98 \\
(21.8 \%)\end{array}$ & $\begin{array}{l}200 \\
(44.4 \%)\end{array}$ & \\
\hline & $\begin{array}{l}\text { To judge which everyday behavior (such as } \\
\text { drinking and eating habits, exercise etc.) is } \\
\text { related to your health? }\end{array}$ & $\begin{array}{l}80 \\
(17.8 \%)\end{array}$ & $\begin{array}{l}68 \\
(15.1 \%)\end{array}$ & $\begin{array}{l}102 \\
(22.7 \%)\end{array}$ & $\begin{array}{l}200 \\
(44.4 \%)\end{array}$ & \\
\hline & $\begin{array}{l}\text { To join a sports club or exercise class if you } \\
\text { want to? }\end{array}$ & $\begin{array}{l}285 \\
(63.3 \%)\end{array}$ & $\begin{array}{l}71 \\
(15.8 \%)\end{array}$ & $\begin{array}{l}50 \\
(11.1)\end{array}$ & $\begin{array}{l}44 \\
(9.8 \%)\end{array}$ & \\
\hline
\end{tabular}

On computing whole scores of health literacy and categorizing them according to operational definition, $118(26.2 \%)$ respondents were found to have poor (HL mean score between 1-2) health literacy, more than half of respondents i.e. 254 (56.4\%) were found to have satisfactory health literacy (HL mean score $>2-<3$ ), whereas only $78(17.3 \%)$ were found to have good health literacy (HL score $>3$ ).

Mean health literacy was compared in different socioeconomic groups as shown in figure 4. It was found to be highest in higher class (3.1), then in middle class (2.5), and least observed mean HL in lower class (2.3). Homogeneity of variance of mean HL in all three groups was assessed using Levene's test; F $(2,477)=2.26, p=0.105$, showing that the variance of mean HL was homogenous in all the groups. As the condition of homogeneity was satisfied, ANOVA test was applied and it showed a significant difference between mean HL in our socioeconomic groups $(\mathrm{F}=5.83, \mathrm{p}=0.003)$.

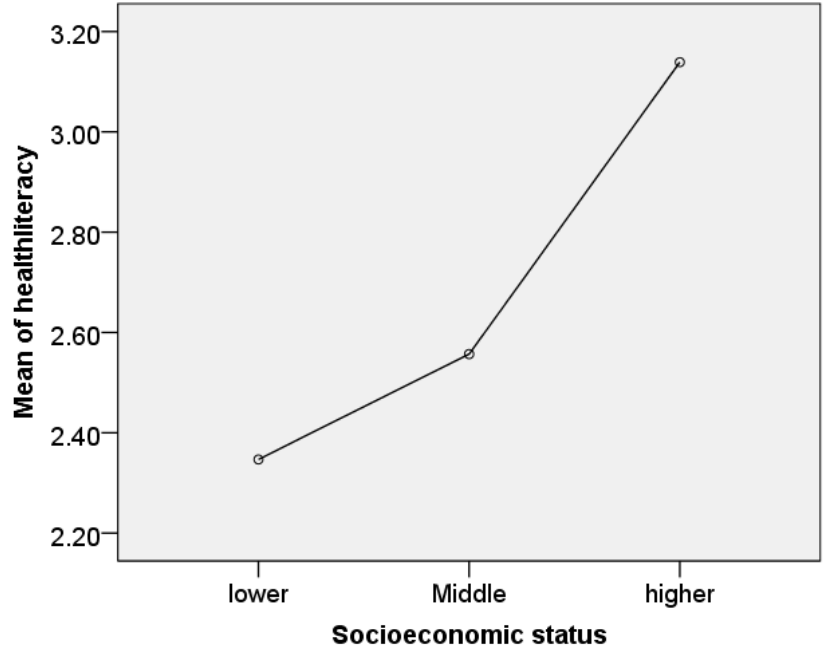

Figure 4. Mean health literacy in relation to socioeconomic status $(n=450)$

Mean health literacy was also comapred in groups of people watching TV often, mostly and never. Mean HL was found to be highest in those watching TV 
mostly (2.7), then in those watching TV often (2.5), and least observed mean HL in those who never watch TV (2.4) as shown in figure 5. Homogeneity of variance of mean HL in all three groups was assessed using Levene's test; $F(2,477)=0.66, p=0.517$, showing that the variance of mean HL was homogenous in all the groups. ANOVA test was applied and it showed a significant difference between mean HL in our socioeconomic groups $(\mathrm{F}=3.3, \mathrm{p}=0.036)$.

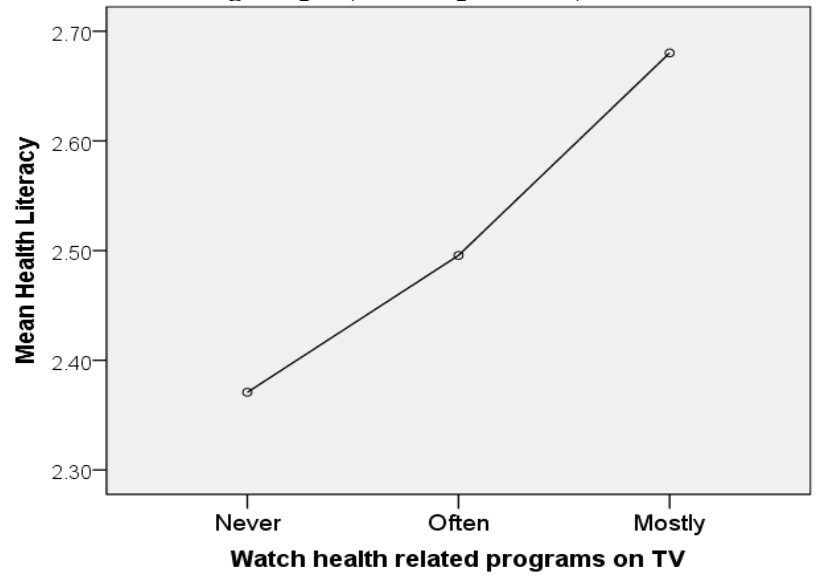

Figure 5: Mean health literacy in relation to frequency of watching TV $(n=450)$

\section{Discussion}

According to this study, $55.5 \%$ patients reported difficulty in understanding the leaflet that comes with their medicine and $52.7 \%$ felt difficulty in judging side effects of different treatments. This may affect their compliance or utilization of medicines (14). This fact is similar to the results of another national study done in Karachi which revealed that $41.7 \%$ patients lacked proper understanding of medication use and $62.58 \%$ of patients lacked knowledge about side-effects of drugs (10). This lack of understanding of medication use must be linked with low levels of education in our nation. As health literacy is strongly dependent on education, the Pakistani population is highly disadvantaged. According to the Pakistan Bureau of Statistics, one-third of the population has primary level education and only $20 \%$ attain middle school education (9).

In our study, we found that $26.2 \%$ study subjects had overall poor literacy. Whereas, in the study done by Karachi, majority patients reported poor literacy levels (10). This maybe because our variables used in measuring health literacy were different from that study. No other national study was available for comparison showing the lack of attention being given to this subject by our health authorities. On the other hand, if we review literature about our neighboring countries, we find that HL is given due attention in China. A National Health Literacy Project in China was developed in 2008 which helped increase health literacy from $6.5 \%$ to $9.8 \%$ in six years (9).

Our study reported that mean HL was significantly different in different socioeconomic groups. It was observed to be higher among people with higher social status $(p=0.003)$. These findings are consistent with a study done in Europe which showed significant relationship between HL and socioeconomic status (15). This consistency in results complements the already established fact of relation between social class and literacy. Also in this European study, only $12 \%^{14}$ participants had insufficient HL as compared to $26.2 \%$ poor literacy in our study. This shows high HL levels in more developed countries.

HL was found to be associated with frequency of watching TV in our study. Those who watched TV more had higher HL. Pakistani media has improved the health literacy of viewers during the last decade (9). This way of mass education by some channel of media has been studied to be a good way of improving health literacy as revealed in a study done in Texas where HL was higher among persons exposed to an online source of health information (16).

\section{Conclusion:}

Majority of the respondents in our study had insufficient health literacy and it was found to be associated with socioeconomic status and frequency of watching TV of study subjects.

\section{Recommendations:}

More research should be done regarding health literacy of our population at large scale. Different versions of European Questionnaire should be validated for use in our population and then used in large scale surveys. Funding should be provided for research in this area. This will reveal important baseline information of literacy level which can be used in designing literacy programs in future.

\section{References:}

1. Cąllşkan C, Üner S. Disaster Literacy and Public Health: A Systematic Review and Integration of Definitions and Models. Disaster Med Public Health Prep. Published online 2020. doi:10.1017/dmp.2020.100 
2. Nutbeam D. The evolving concept of health literacy. Soc Sci Med. Published online 2008. doi:10.1016/j.socscimed.2008.09.050

3. Koay K, Schofield P, Jefford M. Importance of health literacy in oncology. Asia Pac J Clin Oncol. Published online 2012. doi:10.1111/j.1743-7563.2012.01522.x

4. Geboers B, Reijneveld SA, Jansen CJM, de Winter AF. Health Literacy Is Associated With Health Behaviors and Social Factors Among Older Adults: Results from the LifeLines Cohort Study. J Health Commun. 2016;21(0):45-53.

5. Peerson A, Saunders M. Health literacy revisited: What do we mean and why does it matter? Health Promot Int. 2009;24(3):285-296.

6. Duong $\mathrm{T}$ Van, Chang PWS, Yang SH, et al. A New Comprehensive Short-form Health Literacy Survey Tool for Patients in General. Asian Nurs Res (Korean Soc Nurs Sci). 2017;11(1):30-35.

7. HLS-EU-Consortium. HLS-EU-Q Measurement of Health Literacy in Europe: HLS-EU-Q47; HLS-EU-Q16; and HLS-EU-Q86. Exec Agency Heal Consum. Published online 2012:1-14.

8. Pelikan JM, Röthlin F, Ganahl K. Measuring comprehensive health literacy in general populations: validation of instrument, indices and scales of the HLSEU study. 6th Annu Heal Lit Res Conf. Published online 2014.

9. Sabzwari SR. SHORT REVIEW Health literacy in Pakistan: Exploring new ways of addressing an old challenge Present State of Healthcare in Pakistan.
Published online 1901:1901-1904.

10. Saleem F, Hashmi FK, Atif N, et al. A Cross Sectional Assessment of Health Literacy among Cardiovascular Patients in Karachi, Pakistan. Heal Econ Outcome Res Open Access. 2015;01(01):1-4.

11. Saeed H, Saleem Z, Naeem R, Shahzadi I, Islam M. Impact of health literacy on diabetes outcomes: a crosssectional study from Lahore, Pakistan. Public Health. Published online 2018. doi:10.1016/j.puhe.2017.12.005

12. Suhail K. A study investigating mental health literacy in Pakistan. J Ment Heal. Published online 2005. doi:10.1080/09638230500085307

13. Conceptual based short-form health literacy questionnaire (HL-SF12). :12.

14. Owais A, Hanif B, Siddiqui AR, Agha A, Zaidi AK. Does improving maternal knowledge of vaccines impact infant immunization rates? A community-based randomized-controlled trial in Karachi, Pakistan. BMC Public Health. Published online 2011. doi:10.1186/14712458-11-239

15. Sørensen K, Pelikan JM, Röthlin F, et al. Health literacy in Europe: Comparative results of the European health literacy survey (HLS-EU). Eur J Public Health. Published online 2015. doi:10.1093/eurpub/ckv043

16. Ghaddar SF, Valerio MA, Garcia CM, Hansen L. Adolescent health literacy: The importance of credible sources for online health information. J Sch Health. Published online 2012. doi:10.1111/j.17461561.2011.00664.x 